\title{
Structure-to-function relationships of bacterial translocator protein (TSPO): a focus on Pseudomonas
}

\section{Charlène Leneveu-Jenvrin ${ }^{1}$, Nathalie Connil ${ }^{1}$, Emeline Bouffartigues ${ }^{1}$, Vassilios Papadopoulos ${ }^{2}$, Marc G. J. Feuilloley ${ }^{1}$ and Sylvie Chevalier ${ }^{1}{ }^{*}$}

${ }^{1}$ Laboratory of Microbiology Signals and Microenvironment EA 4312, University of Rouen, Evreux, France

${ }^{2}$ Department of Medicine, Research Institute of the McGill University Health Centre, McGill University, Montreal, QC, Canada

\section{Edited by:}

Frank T. Robb, University of Maryland, USA

\section{Reviewed by:}

Henri Batoko, Université Catholique de Louvain, Belgium

Peter Lindemann,

Martin-Luther-Universität, Germany Alexei Yeliseev, National Institutes of Health, USA

\section{*Correspondence:}

Sylvie Chevalier, Laboratory of Microbiology Signals and

Microenvironment EA 4312, University of Rouen, 55 rue Saint Germain, Evreux F-27000, France e-mail: sylvie.chevalier@univ-rouen.fr
The translocator protein (TSPO), which was previously designated as the peripheral-type benzodiazepine receptor, is a 3.5 billion year-old evolutionarily conserved protein expressed by most Eukarya, Archae and Bacteria, but its organization and functions differ remarkably. By taking advantage of the genomic data available on TSPO, we focused on bacterial TSPO and attempted to define functions of TSPO in Pseudomonas via in silico approaches. A tspo ortholog has been identified in several fluorescent Pseudomonas. This protein presents putative binding motifs for cholesterol and PK 11195, which is a specific drug ligand of mitochondrial TSPO. While it is a common surface distribution, the sense of insertion and membrane localization differ between $\alpha$-and $\gamma$-proteobacteria. Experimental published data and STRING analysis of common TSPO partners in fluorescent Pseudomonas indicate a potential role of TSPO in the oxidative stress response, iron homeostasis and virulence expression. In these bacteria, TSPO could also take part in signal transduction and in the preservation of membrane integrity.

Keywords: translocator protein TSPO, bacteria, Pseudomonas, structure, function

\section{INTRODUCTION}

The translocator protein (TSPO), which was initially designated as the peripheral-type benzodiazepine receptor (PBR), was discovered as a diazepam-binding site in kidney (Braestrup and Squires, 1977), and found to be abundant in the outer mitochondrial membrane of steroid-synthesizing cells, including those in the central and peripheral nervous systems (Papadopoulos et al., 2006). Mitochondrial TSPO is associated to the voltage-dependent anionic channel (VDAC; also designated as mitochondrial porin) and to the adenine nucleotide transport protein adenine nucleotide translocase (ANT; McEnery, 1992; Papadopoulos et al., 2006, 2007) or the ATPase family AAA domain-containing 3A protein (Rone et al., 2012), forming a transmembrane hyperstructure (Figure 1A). TSPO has been involved in many physiological functions in mammals, including cell growth and proliferation, immunomodulation, mitochondrial respiration, apoptosis, and adaptation to oxidative stress (Wang et al., 1984; Ruff et al., 1985; Hirsch etal., 1989; Papadopoulos etal., 2006). One of its main functions is its implication in cholesterol import to the inner mitochondrial membrane, the rate-limiting step in steroid hormone biosynthesis (Papadopoulos et al., 1997a). TSPO has been shown to be a high affinity cholesterol-binding protein (Jamin et al., 2005), and to function together with other proteins in a complementary manner and within a large protein complex, to mediate the import of cholesterol into mitochondria (Miller and Bose, 2011; Issop et al., 2013; Poderoso et al., 2013). The function of TSPO as translocator or as acceptor of molecules (including cholesterol) associated with larger membrane translocator complexes is yet still unclear. TSPO drug ligands were shown to significantly affect cell and tissue steroid production and regulate circulating and tissue steroid levels (Krueger and Papadopoulos, 1990; Papadopoulos et al., 1990, 1997b, 2006; Lacapère and Papadopoulos, 2003; Levine et al., 2007; Veenman et al., 2007; Rupprecht et al., 2009, 2010; Chung et al., 2013), indicating that TSPO is required for steroidogenesis. However, recent studies using a Leydig- and Sertoli-cell targeted knock out of the tspo gene (Morohaku et al., 2014) and a tspo null mice (Tu et al., 2014) indicated that the presence of TSPO may not be essential for steroid hormone biosynthesis. Although this raised controversy and several questions regarding mitochondrial TSPO function in steroidogenesis (Papadopoulos, 2014), and essential cell life processes, this does not detract from the fact that TSPO is abundant in steroidogenic cell mitochondria and that drug ligands act specifically on this protein to increase cholesterol import into mitochondria and steroidogenesis (Papadopoulos et al., 1997b, 2006; Lacapère and Papadopoulos, 2003; Levine et al., 2007; Veenman et al., 2007; Rupprecht et al., 2009). Recent structural studies confirmed the proposed structure and function of TSPO drug ligands (Jaremko et al., 2014). TSPO upregulation has been connected to several diseases, including cancer (Batarseh and Papadopoulos, 2010), neuronal damage, neurodegeneration, and inflammation, making the protein an important marker for glial cell activation and neuroinflammation (Harberts et al., 2013; Dickens et al., 2014). Recently, TSPO has attracted attention as a possible molecular target for tumor imaging and chemotherapy (Austin et al., 2013), and initial clinical trials have indicated that TSPO ligands might be valuable in the treatment of neurological and psychiatric disorders (Rupprecht et al., 2010).

Considering these important functions and perspectives in mammals, TSPO has been the focus of multiple studies and 

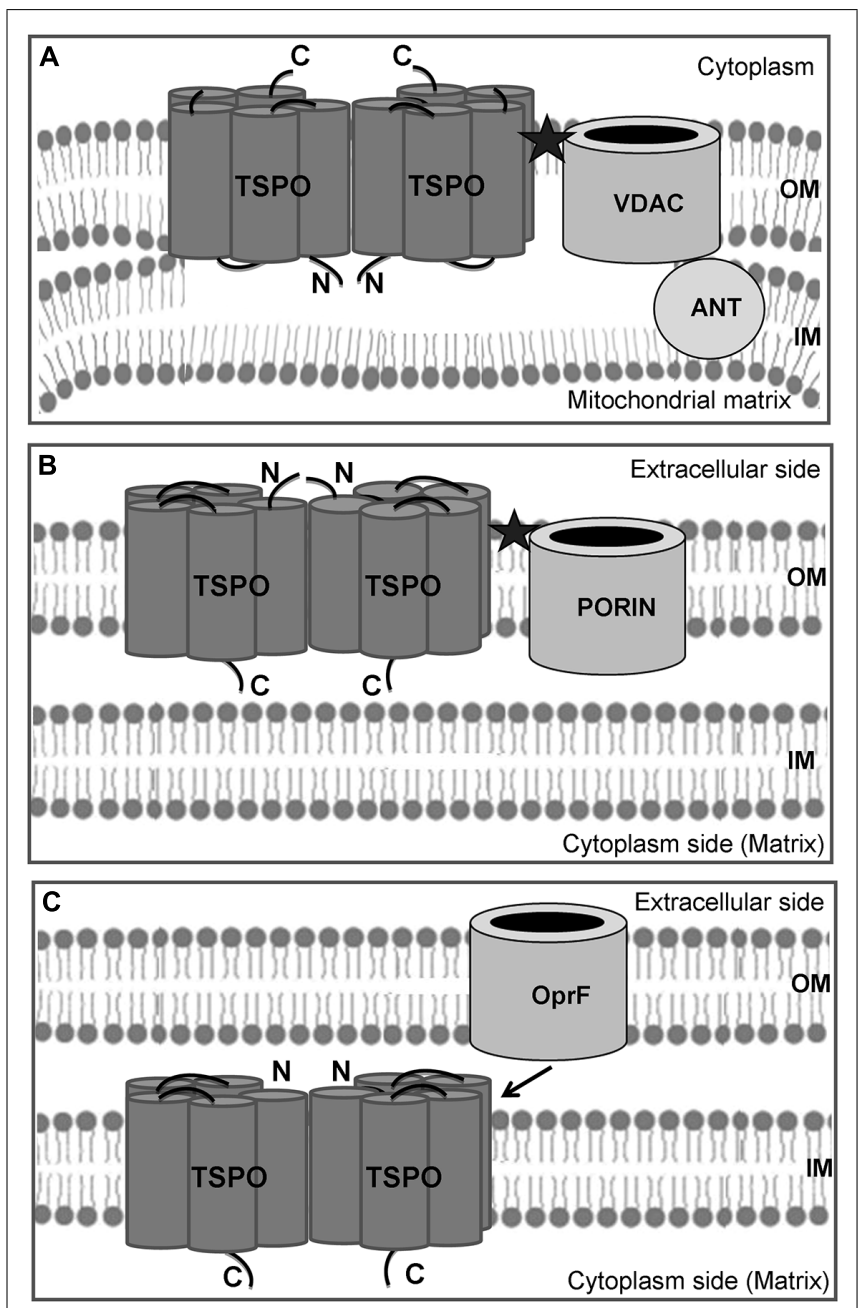

FIGURE 1 | Schematic cellular localization of TSPO. The mitochondrial TSPO is located at the level of the outer-inner mitochondrial membrane contact sites, and it forms a ternary association with the voltage-dependent anionic channel (VDAC) and the adenine nucleotide transport protein (ANT; A). In Rhodobacter sphaeroides 2.4.1, TSPO is also located in the outer membrane, but it is oriented in opposite sense with the C-terminal end facing the cytoplasmic side (B). In Pseudomonas fluorescens, TSPO is oriented in the same sense as in $R$. sphaeroides, but it appears to be located in the inner membrane (C). TSPO has functional relationships with the major outer membrane porin OprF, but the two proteins cannot associate in the same membrane and form a benzodiazepine-binding site $(\star)$, as observed in mitochondria and $R$. sphaeroides.

reviews (Papadopoulos et al., 2006; Rupprecht et al., 2010; Fan et al., 2012). However, it remains a mysterious protein, since functional links between its putative translocation activity and its implication in multiple physiological functions are still lacking (Fan et al., 2012). Since TSPO was conserved throughout evolution in among the great diversity of Eukarya, Archaea, and Bacteria (Chapalain et al., 2009; Fan et al., 2012), and since bacterial and mammalian TSPOs are functionally interchangeable (Yeliseev et al., 1997), it is tempting to assume that the more ancestral cell forms - the bacteria - could provide further insights into the TSPO structure-to-activity relationships. The present study aims to describe bacterial TSPO in terms of its structure and function on the basis of published data and in silico predictive approaches, with a special focus on TSPO belonging to the highly adaptable Pseudomonas genus.

\section{BACTERIAL TSPO STRUCTURE}

The first bacterial protein homolog of PBR was described in the non-sulfurous photosynthetic purple bacterium Rhodobacter sphaeroides by Yeliseev and Kaplan (1995). In that paper, the nomenclature tryptophan-rich sensory protein (TSPO) was proposed. The $17 \mathrm{kDa}$ bacterial protein is composed of 158 amino acids and shows only 33.5 and $21 \%$ of similarity and identity respectively with human TSPO (Yeliseev et al., 1997). Thanks to molecular modeling, $R$. sphaeroides TSPO was proposed to fold into the outer membrane (OM) as five hydrophobic $\alpha$ helix regions, similarly to eukaryotic TSPO (Yeliseev and Kaplan, 2000), suggesting that the protein was conserved at the topological rather than at the amino acid sequence level. The postulated functional form of R. sphaeroides TSPO is a homodimer (Yeliseev and Kaplan, 2000). The three-dimensional structure of mammalian TSPO in complex with the PK 11195 drug ligand was recently reported and confirmed the previously reported TSPO topography, drug and cholesterol-binding sites as well as provided a model for ligand induced cholesterol transport (Jaremko et al., 2014). However, as shown in Figures 1A,B, the R. sphaeroides and mitochondrial TSPOs are proposed to be inserted in opposite directions, i.e., the N-terminus is exposed to the extracellular side of the bacterial protein (Yeliseev and Kaplan, 2000), while it is located at the interface of the inner and outer mitochondrial membranes. One hypothesis that may account for this particularity is that while in bacteria, the protein is produced in the cytoplasm and then addressed into the OM from the inside, in eukaryotes the tspo gene has been translocated to the nuclear DNA (Gray et al., 2001) probably a billion years ago; therefore, TSPO is synthesized in the cell's cytoplasm and inserted in the mitochondrial membrane from the outside via translocase Tom70 (Otera et al., 2007) and metaxin 1 (Rone et al., 2009). The localization of TSPO in the OM of $R$. sphaeroides is further consistent with the observation that benzodiazepines such as flunitrazepam can crosslink TSPO to its major OM porin, as occurs in mammals (Yeliseev and Kaplan, 1995). This association may indeed improve the recognition of benzodiazepines in mammals, since the binding site for these artificial ligands could be located in the cleft between the two proteins (Figure 1, black star; McEnery, 1992; Lacapère et al., 2001; Veenman et al., 2007), albeit TSPO alone could be involved in the mitochondrial protoporphyrin IX (PPIX) import (Wendler et al., 2003).

\section{FUNCTIONS}

As in Eukarya, the postulated roles of TSPO in bacteria are numerous, but we can begin to identify their common general functions. The first periplasmic loop of $R$. sphaeroides TSPO contains a high percentage $(22 \%)$ of tryptophan residues, reflecting possibly a WWD heme-binding domain that is typical of proteins involved in heme membrane transport (Goldman et al., 1998). Mitochondrial TSPO was previously shown to bind PPIX (Kinnally et al., 1993; Taketani et al., 1995), suggesting that TSPO may have a role 
in mitochondrial processing of PPIX via the heme synthesis pathway (Furre et al., 2005; Veenman et al., 2007). In R. sphaeroides, TSPO appears to be involved in controlling the efflux of tetrapyrrole intermediates of the heme/bacteriochlorophyll biosynthetic pathway, and it could act as a negative regulator of photosynthetic gene expression and pigment synthesis in response to variations of oxygen and/or light availability (Yeliseev and Kaplan, 1995). The mechanism by which TSPO in Rhodobacter controls the transport of porphyrins remains to be determined. Interestingly, in the plant Arabidopsis thaliana (At), AtTSPO has been proposed to participate in the interactions between the plastidal and the mitochondrial tetrapyrrole biosynthetic pathway (Lindemann et al., 2004). This complex function of TSPO in the response to environmental conditions was confirmed in $R$. capsulatus, where TSPO is highly expressed in anaerobic conditions and in the absence of light (Bauer, 2004). TSPO indeed down-regulates transcription of bacterio-chlorophyll and carotenoid biosynthesis genes, as well as the puc operon, which encodes the structural proteins of the light-harvesting-II peripheral antenna complex (Yeliseev et al., 1997). The role of TSPO appears to be similar in cyanobacteria since it was shown to control photosynthetic genes expression in Synechococcus (González et al., 2011). Similarly, TSPO could be involved in the rapid shut down of the photosynthesis gene cluster in response to oxygen variations in the phototrophic bacterium, Dinoroseobacter shibae (Tomasch et al., 2011), and in the regulation of gene expression by light in the marine flavobacterium Dokdonia (González et al., 2011). More generally, TSPO has been proposed by Yeliseev et al. (1997) as an "oxygen sensor." This protein could control porphyrin efflux by modulating the antirepressor/repressor AppA/PpsR system implicated in the regulation of photosynthetic gene expression in response to changes in oxygen partial pressure (Oh and Kaplan, 2001; Zeng and Kaplan, 2001). Noticeably, this activity is not specific to bacterial TSPO, since a mitochondrial tspo gene provided in trans in $R$. sphaeroides can replace the bacterial TSPO oxygen sensor function (Yeliseev et al., 1997). Interestingly, in the symbiotic Sinorhizobium meliloti, TSPO and FixL, an oxygen sensor, are involved in regulating the expression of the $n d i$ locus that is specifically induced in nutrient (oxygen, carbon, nitrogen) deprivation conditions. TSPO appears to be epistatic to FixL, since no expression is observed in the tspO mutant, even though FixL is still present (Davey and de Bruijn, 2000). Further investigations are necessary to determine if these related TSPO homologs function in a similar manner and respond to the same signals. Nonetheless, these data suggest that TSPO is involved in regulating gene expression and is likely to provide a new and important way to think about signal transduction in prokaryotes.

\section{TSPO IN Pseudomonas GENOMIC ORGANIZATION, SEQUENCES, AND TOPOLOGY CONSERVATION}

The structure-activity relationships of TSPO have been particularly investigated in Pseudomonas fluorescens MF37 (Chapalain et al., 2009). Here we have identified a tspo ortholog gene in 7 of the 48 fully sequenced genomes of Pseudomonas ${ }^{1}$ (Winsor et al.,

\footnotetext{
${ }^{1}$ http://www.pseudomonas.com
}

2011), among which are three Pseudomonas syringae ( $p v$. phaseolicola 1448A, pv. syringae B728a, and pv. tomato DC3000), three Pseudomonas fluorescens (strains SBW25, Pfl0-1, A506), and one Pseudomonas poae (strain $\left.\mathrm{RE}^{\star} 1-1-14\right)$. In silico analysis will thus be focused on these strains. The genomic environment of tspo is not conserved among these seven strains, as previously described (Chapalain et al., 2009), although some degree of conservation exists in each species. For example, in two of the three studied Pseudomonas fluorescens strains, SBW25 and A506, tspo forms an operonic structure with an esterase-encoding gene that is involved in lipid metabolism ${ }^{1}$ (Winsor et al., 2011). Many transposaseencoding genes were found in the vicinity of tspo in the three Pseudomonas syringae strains. Transposases are usually included in autonomous mobile genetic elements, such as transposons or insertion sequences, and they are required for excising and inserting the mobile element, suggesting that in these three strains, tspo acquisition may be the result of an ancient horizontal transfer. Moreover, TSPO could be functionally related to PSPPH_2782 (a transposase of Pseudomonas syringae pv. phaseolicola $1448 \mathrm{~A}^{2}$ ), but the guanine-cytosine (GC) ratio of Pseudomonas syringae tspo is the same as in the rest of its genomic environment, suggesting that if tspo was acquired by insertion, the event was ancient.

Base-pairing comparisons using the MultAlin algorithm ${ }^{3}$ showed that TSPO was highly conserved among these seven strains at both the nucleotide and amino acid sequence levels, with similarities ranging from 71.6-91.1 and 76-95.9\%, respectively. Protein secondary motifs were also conserved in Pseudomonas since a TopPred analysis ${ }^{4}$ revealed that TSPO folds into five putative transmembrane $\alpha$-helixes (Figure 2: T1-T5), similarly to $R$. sphaeroides and mitochondrial TSPO (Chapalain et al., 2009).

However, Pseudomonas TSPO was predicted to fold into the inner membrane (Figure 1C; Chapalain et al., 2009), whereas $R$. sphaeroides TSPO was predicted to insert in the OM as mitochondrial TSPO (Figure 1B, Yeliseev and Kaplan, 2000). This is consistent with the observation that in Escherichia coli, a recombinant eukaryotic protein was essentially retrieved from inner membrane extracts (Yeliseev et al., 1997), suggesting the different localization of TSPO in $\alpha$ - and $\gamma$-proteobacteria (Chapalain et al., 2009). Furthermore, the orientation of this insertion was in the opposite direction with respect to Pseudomonas and $R$. sphaeroides TSPO: in the case of Pseudomonas TSPO, the N-terminus was inserted into the inner membrane; conversely, it is exposed at the bacterial surface in R. sphaeroides (Figures 1B,C). Interestingly, in mammals, TSPO was also found in the cytoplasmic membrane (Oke et al., 1992; Woods and Williams, 1996; Woods et al., 1996), suggesting that TSPO could exert functions at different levels, including on the cell surface or outside the cell.

In addition, the potential PK 11195 binding motif LxKPsW/F, previously determined by Fan et al. (2012), was identified in the first loop (Figure 2). This motif was fully conserved among the seven TSPO sequences of fluorescent Pseudomonas, suggesting it

\footnotetext{
${ }^{2}$ http://www.ncbi.nlm.nih.gov/gene/3559346

${ }^{3}$ http://multalin.toulouse.inra.fr/multalin/multalin.html

${ }^{4}$ http://www.pasteur.fr/
} 


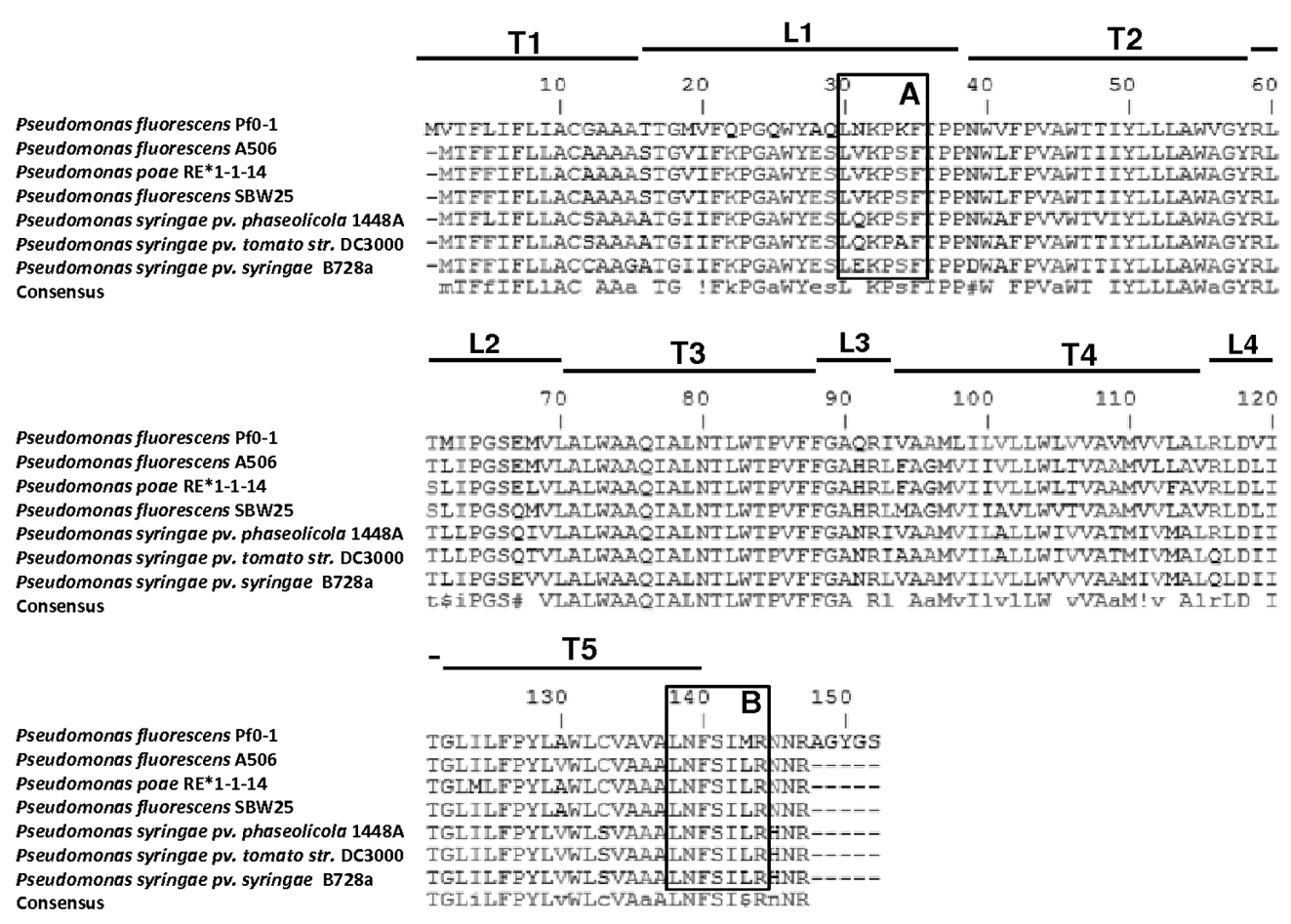

FIGURE 2 | Amino acid sequence alignment of TSPO from sequenced Pseudomonas genomes, including Pseudomonas fluorescens (strains Pf0-1, SBW25, A506), Pseudomonas poae (strain RE*1-1-14), and Pseudomonas syringae (strains 1448A,
DC3000, B728a). Framed are A) the PK 11195 binding site LxKPsW/F (Fan etal., 2012), and (B) the CRAC motif L/V/I-(X) 1-5-Y-(X)1-5-R/K (Fan etal., 2012). T, transmembrane segment; L, Loop. may play a function in Pseudomonas TSPO. This binding motif was mapped onto the recently reported $3 \mathrm{D}$ structure of mouse TSPO just outside of the PK 11195 binding pocket and it consists of 65 contacts between the ligand and TSPO involving the five transmembrane domains (Jaremko et al., 2014). PK 11195 is an isoquinoline carboxamide drug ligand of the mitochondrial TSPO, whose binding site is exclusively located on TSPO (Le Fur et al., 1983). The use of PK 11195 in Pseudomonas fluorescens MF37 allowed researchers to demonstrate that there was a functional association between TSPO and the major OM porin OprF since the biological activity of PK 11195 was totally abolished in an OprF deletion mutant (Chapalain et al., 2009). Moreover, the affinity of PK 11195 for Pseudomonas fluorescens MF37 TSPO was the same as for mitochondrial TSPO, indicating the preservation of common properties between the two proteins (Chapalain et al., 2009). However, in normal and low-oxygen conditions, PK 11195 was without effect on the growth kinetics of Pseudomonas fluorescens MF37 (Chapalain et al., 2009), suggesting that it should not act as an oxygen sensor as in R. sphareoides (Yeliseev et al., 1997). The localization of TSPO in the OM of R. sphaeroides is consistent with the observation that benzodiazepines such as flunitrazepam can crosslink TSPO to its major OM porin, as in mammals (Yeliseev and Kaplan, 1995). While in mitochondria TSPO and VDAC are in the same (outer) membrane where they can associate to form a diazepam-binding site (Figures 1A,B), in Pseudomonas fluorescens, TSPO and porins (such as OprF) should be inserted in the inner and OMs, respectively (Figure 1C). This can explain the absence of sensitivity of Pseudomonas fluorescens to diazepam (our unpublished data) since, if TSPO also interacts with porin(s), the structure of the complex should be different. The conservation of the PK 11195 binding motif in the bacterial TSPO sequences suggests that molecules mimicking the structure of PK 11195 might interact with TSPO. The association of bacterial TSPO with OprF in case of Pseudomonas fluorescens MF37, or the major OM protein in case of $R$. sphaeroides further suggest that TSPO might be the binding site for such molecules and that it is associated with larger membrane channels, relatively similarly to mitochondrial TSPO associated to VDAC.

Taken together, these data show that Pseudomonas TSPO shares common structural properties with $R$. sphaeroides and mitochondrial TSPOs. It should be noted that the most intriguing observation included the topological differences found among several of the proteins between eukaryotic and prokaryotic TSPOs; however, the most striking difference was seen between $R$. sphaeroides and Pseudomonas TSPOs, suggesting that they hold common yet specific functions.

\section{PUTATIVE FUNCTIONS}

The functional role of TSPO in these bacteria appears to be at least as essential as in $R$. sphaeroides, since while in this species a knock-down of TSPO is possible (Yeliseev and Kaplan, 1995), any major change of TSPO expression (positively or negatively) in all investigated strains of Pseudomonas fluorescens is lethal (Chapalain et al., 2009). 


\section{TSPO and cholesterol/steroidogenesis}

As described in the introduction section, one of the functions of mitochondrial TSPO is its involvement in cholesterol import into mitochondria, which is a prerequisite for steroidogenesis - a function which was recently questioned due to the absence of observed effects on steroidogenesis in a tspo-null mice mutant- (Morohaku etal., 2014; Tu etal., 2014). Although these findings argue that cholesterol import into mitochondria may occur in the absence of TSPO, they do not indicate that in normal cells this process is not mediated by TSPO, a protein abundant in the outer mitochondrial membrane. Noticeably, the potential cholesterol recognition amino-acid consensus (CRAC) L/V/I- $(\mathrm{X})_{1-5}-\mathrm{Y}-(\mathrm{X})_{1-5}-\mathrm{R} / \mathrm{K}$, previously determined in mammals by $\mathrm{Li}$ and Papadopoulos (1998), and shown to be common among many proteins (Fantini and Barrantes, 2013), and its evolution reviewed by Fan et al. (2012), was identified in the C-terminal part of TSPO (Figure 2). The CRAC motif lacked the internal characteristic $\mathrm{Y}$ of eukaryotes (Figure 2). This feature, associated with the absence of cholesterol in bacterial membranes, prompted Fan et al. (2012) to suggest that this motif is rarely found in bacterial TSPO sequences. Notably, this sequence was highly conserved among the seven Pseudomonas TSPOs, suggesting that this C-terminal part has a special function in the TSPO role in these bacteria. Cholesterol has not yet been found to be produced in bacteria. However some steroids, among which cycloartenol, the first oxidosqualene cyclization product in plants (Bode et al., 2003), or lathosterol, a molecule closely structurally-related to cholesterol, have been shown to be produced by several Myxobacteria species as well as by Methylococcus capsulatus (Bird et al., 1971; Tippelt et al., 1998; Bode et al., 2003; Gawas et al., 2011). Moreover, a phylogenetic study of the sterol biosynthesis pathways reported that some other bacterial genomes may possess certain genes which products could be involved in sterol biosynthesis pathways. In particular, this study reported that Myxobacterium Plesiocystis pacifica harbors the largest reported set of eukaryotic sterol-synthesizing enzyme homologs (Desmond and Gribaldo, 2009), suggesting that this Myxobacterium could be at the origin of these eukaryotic enzymes (López-Garćia and Moreira, 1999). It is also likely that Plesiocystis pacifica has acquired its pathway for sterol synthesis via horizontal gene transfer from eukaryotes (Desmond and Gribaldo, 2009).

In the Myxobacteria Nannocystis exedens, almost all known intermediates and side-products of the cholesterol biosynthesis in eukaryotes can be found under different culture conditions (Bode et al., 2003). Although the authors clearly demonstrate that Myxobacteria can produce as much steroids as eukaryotic organisms, the function of these compounds remains a mystery. Due to their hydrophobicity, these molecules are most probably located in membranes, where they might have a function in controlling fluidity, in a manner similar to that described for cholesterol in eukaryotes (Ourisson and Nakatani, 1994). An additional function of the myxobacterial steroids might be to act as signaling molecules, similar to steroid hormones (Porter et al., 1996). Interestingly, a TSPO homolog has been predicted in some Myxobacteria species ${ }^{5}$.

\footnotetext{
${ }^{5}$ http://www.uniprot.org/
}

To date, no Pseudomonas species has been shown to produce such compounds, and the genes encoding the required enzymes are actually not predicted in the Pseudomonas database ${ }^{1}$. It may be conceivable that these bacteria could perceive or transport exogenous cholesterol or even structurally-related tetracyclic molecules like hopanoids for example (Fan et al., 2012). It is also possible that the functions of the Pseudomonas TSPO were evolutionary older, and that the possible involvement of mitochondrial TSPO in cholesterol transport and steroidogenesis occurred much later.

\section{TSPO and iron homeostasis}

To get further insights into the putative protein functions in Pseudomonas, TSPO's functional interactions were retrieved from STRING database (von Mering etal., 2007), in Pseudomonas syringae (strains B728a, 1448A and DC3000) and Pseudomonas fluorescens (strains SBW25, Pfl0-1) since STRING data were not available for either Pseudomonas fluorescens A506 or Pseudomonas poae RE*1-1-14. STRING is a database of known and predicted protein interactions, including physical and functional associations, which are derived from four sources including genomic context, high-throughput experiments, coexpression and literature. Only interactions with high confidence levels $(>0.7)$ were kept. Common TSPO partners in each of the five studied strains were then represented as a Venn diagram (Figure 3; Chen and Boutros, 2011). This STRING-based study should be understood as a first hint where to search.

HemE is found to interact with TSPO in each of the studied strains, as well as in R. sphaeroides and Sinorhizobium meliloti (STRING), suggesting a putative robust link between the two proteins. HemE is an uroporphyrinogen-III decarboxylase that produces coproporphyrinogen III, also called apoferritin. Ferritin

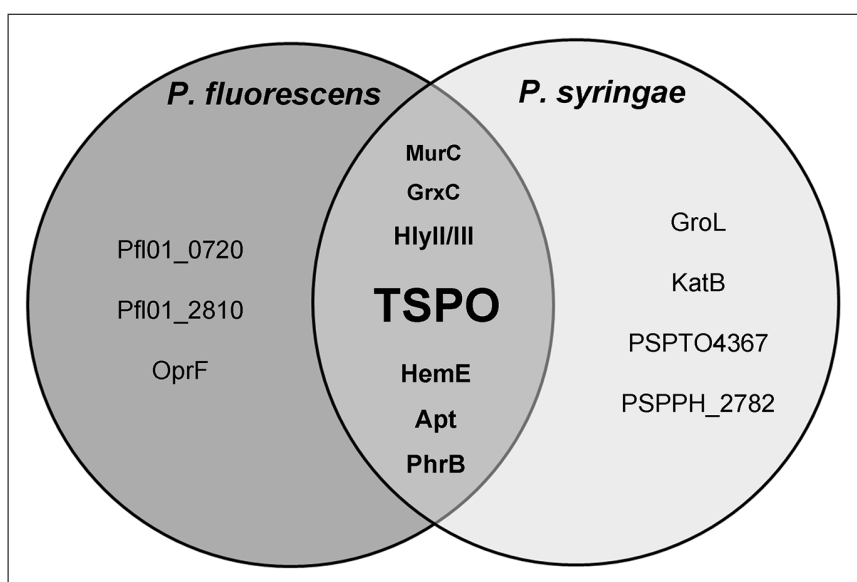

FIGURE 3 | Representation of the predicted interactions of TSPO in fluorescent Pseudomonas. This Venn diagram was established using STRING version 9.05 software. Apt: adenine phosphoribosyl transferase; GroL, chaperone subunit; GrxC, monothiol glutaredoxin; HemE, uroporphyrinogen-III decarboxylase; Hlyll/III, haemolysin II/III; KatB, catalase; MurC, UDP-N-acetylmuramate-L-alanine ligase; PhrB, type 1 deoxyribodipyrimidine photo-lyase; OprF, major outer membrane porin; PfI01_0720, NAD-dependent epimerase/dehydratase; Pfl0-1_2810, PAS/PAC sensor HyHK histidine kinase; PSPTO4367, ortholog of the thiol oxydoreductase; PSPPH_2782, transposase. 
and ferritin-like molecules store $\mathrm{Fe}^{3+}$ as a mineral in their hollow cavities, effectively concentrating iron levels to orders of magnitude higher than those permitted by its low solubility (Yao et al., 2011). Iron is required by most organisms, but it is potentially toxic due to its low solubility, and to its tendency to potentiate the production of reactive oxygen species (ROS). The reactivity of iron is counteracted by bacteria using the same strategies employed by eukaryotes, namely by sequestering the metal into ferritin. These pivotal contributions made by ferritin-like molecules to iron homeostasis are manifested by their presence in all three domains of life with remarkable conservation of structure and function, despite very low sequence conservation $(<20 \%$; Grossman et al., 1992).

In addition to this major function in iron scavenging, apoferritin is also an intermediate of porphyrin and heme biosynthesis. Notably, in R. sphaeroides, TSPO has been shown to act as a negative regulator in the expression of hemN (Yeliseev and Kaplan, 1999), encoding a protein involved in heme trafficking. In mammals, coproporphyrinogen III is transported into the mitochondrial space where its conversion to PPIX takes place. PPIX is then converted into PPIX, which then sequester iron $\left(\mathrm{Fe}^{2+}\right)$, thus forming heme (Kabe et al., 2006). The intra-mitochondrial accumulation of PPIX in response to iron starvation is toxic, and TSPO has been involved in mitochondrial detoxification, at least partly through PPIX export (Yeliseev and Kaplan, 1999; Mesenholler and Matthews, 2000). Remarkably, in the plant A. thaliana, in which heme biosynthesis is mainly localized in plastids (Mochizuki et al., 2010), TSPO has been proposed to participate in the interaction between the plastidal and the mitochondrial tetrapyrrole biosynthetic pathway, most likely by transporting the protoporphyrinogen from the plastids to the mitochondrial site of heme formation (Lindemann et al., 2004). Plant TSPO is also involved in scavenging unbound heme and porphyrins (Vanhee et al., 2011), and has recently been proposed to function as an autophagy receptor for toxic porphyrins leading to their specific degradation (Veljanovski and Batoko, 2014). Recently, bacterial TSPOs have been shown to catalyze rapid porphyrin degradation in a light- and oxygen-dependent manner - a reaction that is inhibited by the synthetic TSPO ligand, PK 11195 - and by mutations of conserved residues, which affect either porphyrin binding or catalytic activity (Ginter et al., 2013). Taken together these data suggest that TSPOs are ancient evolutionary conserved enzymes mediating porphyrin catabolism most likely with the consumption of ROS (Ginter et al., 2013).

\section{TSPO and oxidative stress response}

Iron is both an essential nutrient for the growth of microorganisms, as well as a dangerous metal due to its capacity to generate ROS via the Fenton reaction. For these reasons, bacteria must tightly control the uptake and storage of iron in a manner that restricts the build-up of ROS. Therefore, the control of iron homeostasis and responses to oxidative stress are intimately coordinated (Cornelis, 2010). The link between TSPO and the response to ROS is strengthened by the fact that several proteins that are involved in the oxidative stress response were predicted to interact with Pseudomonas TSPO. This was the case for example of the monothiol glutaredoxin GrxC that was found in fluorescent Pseudomonas TSPO interactome (Figure 3), which is involved in the bacterial oxidative stress response and in iron homeostasis (Cabiscol et al., 2000). In E. coli, GrxC is able to bind to glutathione, helping to maintain the redox status of the cell (Lillig et al., 2008). GrxC can then reduce the oxidized redox-response master regulator OxyR, thus creating a feedback loop that regulates OxyR activity (Zheng et al., 2001). In addition, GrxC is also a player in iron homeostasis, since it has been shown to bind $\mathrm{Fe}-\mathrm{S}$ clusters, and it is also involved in some aspects of $\mathrm{Fe}-\mathrm{S}$ cluster biogenesis and regulation (Iwema et al., 2009; Couturier et al., 2011; Boutigny etal., 2013). In the fungi, Saccharomyces cerevisiae and Schizosaccharomyces pombe, GrcX also plays essential roles in intracellular iron signaling, iron trafficking, and maturation of Fe-S cluster proteins (Mühlenhoff et al., 2010; Mapolelo et al., 2013). Common to each of the studied Pseudomonas TSPO functional networks is also $\mathrm{PhrB}$ (Figure 3), a conserved photolyase, the structure of which contains a [4Fe-4S] cluster as a cofactor bound to the catalytic domain (Zhang et al., 2013). Of note, PhrB was also predicted to interact with $R$. sphaeroides TSPO (STRING). Photolyases are enzymes involved in DNA repair and cell cycle regulation under stress conditions, which are commonly associated with the bacterial SOS response (Aravind et al., 2013). Interestingly, in mammals, mitochondria are the central cellular compartment for $\mathrm{Fe}-\mathrm{S}$ cluster biogenesis, which is implicated in mitochondrial respiration and DNA repair (Stehling et al., 2014). Thanks to their chemical versatility, Fe-S centers act as catalysts or redox sensors (Stehling et al., 2014), and they are thought to rank among the most ancient and versatile inorganic cofactors found in all kingdoms of life (Beinert et al., 1997). The link between TSPO and ROS is further strengthened by the predicted interactions between Pseudomonas syringae TSPOs and both catalase KatB and orthologs of the thiol oxydoreductase PSPTO4367 (Figure 3), which are two key enzymes in almost all living organisms that are used to protect themselves against oxidative stress (Cabiscol et al., 2000; Mishra and Imlay, 2012). Interestingly, KatB was also linked to TSPO in Sinorhizobium meliloti (STRING data not shown).

In mammals, the mitochondrial location of the TSPO is interesting as it is well known that mitochondria are a main source of cellular ROS (Lenaz, 1998). It has been shown that oxidative stress modulates TSPO structure and function (Delavoie et al., 2003). Increased ROS levels lead indeed to TSPO polymerization through di-tyrosine formation, which modulates the function of TSPO in cholesterol transport, since polymer formation induced by ROS increased both TSPO ligand binding and cholesterolbinding capacities (Delavoie et al., 2003). Vice versa, TSPO appears to be an essential participant in ROS generation at mitochondrial levels (Veenman et al., 2007; Zeno et al., 2009; Choi et al., 2011). In the liver, TSPO was found in co-localization with a ROS scavenger, the mitochondrial manganese-dependent superoxide dismutase (SOD; Fischer et al., 2001). In the moss plant Physcomitrella patens (Pp), Pptspo1 knockout mutants were shown to be impaired in their mitochondrial PPIX uptake and produced elevated levels of intracellular ROS, implying a role of PpTSPO1 in redox homeostasis (Frank et al., 2007; Vanhee et al., 2011). TSPO-deficient plants were shown to be under permanent oxidative stress and 
suffer from disturbed redox homeostasis (Lehtonen et al., 2012). Abiotic stresses, among which salt, drought or cold, transiently upregulate heme biosynthesis that is required for the activity of ROS scavengers, and simultaneously induce the expression of TSPO (Frank et al., 2007). In A. thaliana, AtTSPO is expressed in dry seeds and can be induced in vegetative tissues by osmotic and salt stresses or by abscisic acid (ABA) treatments, suggesting that AtTSPO is specifically induced by water-related stress (Guillaumot et al., 2009a; Balsemão-Pires et al., 2011). Interestingly, the stress phytohormone ABA regulates plant water status through regulation of stomatal closure (Finkelstein et al., 2002; Nambara and Marion-Poll, 2005). The increase in active ABA levels in plant cells during water-related stress regulates the expression of ABAresponsive genes, among which tspo (Guillaumot et al., 2009a,b; Balsemão-Pires et al., 2011).

Taken together, these data suggest that Pseudomonas TSPO belongs to an evolutionarily conserved coordinated network that is involved in controlling iron and redox homeostasis.

\section{Virulence}

TSPO was predicted to interact with hemolysin II/III (Figure 3, HlyII/III). These proteins are exoenzymes that exhibit cytolytic activity against eukaryotic cells, which are involved in retrieving iron from eukaryotic heme (Guillemet et al., 2013). Such enzymes belong to the virulence factor arsenal of pathogenic bacteria, which enable bacterial survival among hosts in which the iron concentration is limited (Cornelis, 2010). The link between TSPO and virulence is also supported by a recent transcriptomic study in which tspo expression was increased in Pseudomonas syringae sp. phaseolicola NPS3121 cultured at a low $\left(18^{\circ} \mathrm{C}\right)$ rather than at an optimal $\left(28^{\circ} \mathrm{C}\right)$ growth temperature (Arvizu-Gomez et al., 2013). Interestingly, low temperature is the cue for pathogens to produce virulence factors, including toxins, cell wall-degrading enzymes, and effector proteins (Picot et al., 2004; Arvizu-Gomez etal., 2013), suggesting that TSPO may be part of a virulence-related network. It is interesting to note that in Pseudomonas syringae pv. syringae $\mathrm{B} 728 \mathrm{a}$ and in Pseudomonas syringae pv. tomato DC3000, tspo is located in the vicinity near genes that encode homologs of virulence factors, SrfB and SrfC, of Salmonella enterica (Chapalain et al., 2009). These data are also in agreement with those showing that TSPO should be related to the expression of the cytotoxic activity of Pseudomonas fluorescens (Chapalain et al., 2009). Interestingly, PK 11195 was shown to increase adhesion and biofilm formation activities while decreasing the cytotoxic (apoptotic) effect of Pseudomonas fluorescens MF37 (Chapalain et al., 2009). These observations are consistent with the fact that the growth of Pseudomonas in biofilms or aggregates is associated with a decrease in virulence (Staudinger et al., 2014), and this supports the hypothesis that, as in Pseudomonas syringae, TSPO is involved in virulence expression.

In the three studied Pseudomonas syringae strains, the STRING analysis predicted that TSPO interacts with the chaperone subunit, GroL (Figure 3), a protein that belongs to the heat shock sigma factor RpoH regulon. Since $\mathrm{RpoH}$ is involved in the response to stresses leading to misfolded or aggregated proteins, it suggests that TSPO may be linked to this type of general stress response. Interestingly, such functions have been proposed in plant TSPOs (Balsemão-Pires et al., 2011). Furthermore, in addition to their well-documented function as molecular chaperones, GroEL proteins are increasingly recognized as exhibiting surprising additional so-called "moonlighting" functions (Henderson et al., 2013). Perhaps the most astonishing feature of members of the GroEL family is that they can demonstrate toxic activities against eukaryotes (Kupper et al., 2014).

\section{Membrane and cell wall biogenesis and/or integrity}

TSPO was also predicted to interact with three proteins involved in membrane and cell wall biogenesis, including a putative nucleoside-diphosphate-sugar epimerase Pfl01_0720, the UDP$\mathrm{N}$-acetylmuramate-alanine ligase MurC, and OprF (Figure 3). OprF is the major OM porin of members belonging to the Pseudomonas genus, which is homologous to the mitochondrial VDAC. Functional links between OprF and TSPO have been demonstrated in Pseudomonas fluorescens MF37 (Chapalain et al., 2009). Notably, in addition to its structural role in anchoring the OM to the peptidoglycane layer, OprF has been shown to be required for full virulence expression in the human pathogen Pseudomonas aeruginosa (Fito-Boncompte et al., 2011). OprF is also a receptor for human IFN $\gamma$, allowing the bacteria to sense the host's immune state (Wu etal., 2005). Since all of the Pseudomonas are not pathogens, it has further been proposed that this protein could act as a more general environmental sensor (Wagner et al., 2006). The interaction between TSPO and OprF suggests that they could participate in a common sensing/transducing network. This hypothesis is also supported by the observation of a possible functional link between TSPO and the adenine phosphoribosyl transferase (Apt, Figure 3), which enables the transfer of a phosphoribosyl group on adenine, thus producing AMP (Becerra and Lazcano, 1998). Interestingly, in mammals, TSPO is possibly associated with an ANT, which is localized in the inner membrane of mitochondria, and it plays an essential role in transporting ADP into the mitochondrial matrix and ATP out from the matrix for cell utilization (Leung et al., 2013). As such, we cannot exclude that as in eukaryotes, bacterial TSPO should form a ternary complex with an adenine-associated substrate translocating protein.

\section{Signaling and signal transduction}

As mentioned in Section "Functions", TSPO has been shown to be involved in gene regulation, noticeably in $R$. sphaeroides, in which TSPO has been proposed as an oxygen sensor (Yeliseev et al., 1997), and in Sinorhizobium melilotti (Davey and de Bruijn, 2000). In the latter, TSPO is involved in regulating the expression of the nutrient deprivation induced ( $n d i)$ locus. In this bacterium, the two component sensor FixL, has been shown to be required for full induction of the ndi locus expression. Interestingly, these authors demonstrate that TspO appears to be epistatic to the histidine kinase $(\mathrm{HK})$ FixL, since no expression is observed in the tspO mutant, even though FixL is still present (Davey and de Bruijn, 2000). Using the STRING algorithm to investigate the putative interactions of TSPO in Pseudomonas fluorescens Pf0-1, we observed a potential link between TSPO and a hybrid HK ( $\mathrm{HyHK}$, Pfl0-1_2810; Figure 3). Moreover, in this bacterium, the two genes 
appear to be located in the same operonic structure ${ }^{1}$, suggesting the presence of genetic and functional links. Two component signal transduction systems generally consist of a sensor $\mathrm{HK}$ and a response regulator (RR) that contains a receiver or response regulator domain (REC). Hybrid-type HKs (HyHKs) comprise a $\mathrm{HK}$ with a receiver domain within one molecule (Stock et al., 2000). Interestingly, the Pseudomonas fluorescens PfO- $1 \mathrm{HyHK}$ is predicted to possess six functional domains, among which three PAS domains (Figure 4). In the bacterial kingdom, PAS domains are commonly positioned at the amino terminus of signaling proteins such as sensor HKs, and tandem and multiple PAS domains are common in individual proteins: about one third of PAS proteins contain two or more PAS domains (Henry and Crosson, 2011). Interestingly, PAS ligand binding either functions as a primary cue to initiate a cellular signaling response or provides the domain with the capacity to respond to secondary physical or chemical signals such as gas molecules, redox potential, or photons (Henry and Crosson, 2011). Noticeably, many PAS-domain proteins detect their signal by way of an associated cofactor such as heme (Henry and Crosson, 2011), and this may be the case for the Pseudomonas fluorescens $\mathrm{Pf} 0-1 \mathrm{HyHK}$ since a heme pocket has been predicted in each of the three PAS domains (Figure 4). Interestingly, the Pseudomonas fluorescens Pf0-1 HyHK shows some domain similarities with the rice pathogen Xanthomonas oryzae pv. Oryzae, HyHK StoS (i.e., the four C-terminal domains), as it includes a PAS domain with a heme pocket involving StoS as an oxygen sensor, a HisKa dimerization and phosphotransfer domain with an $\mathrm{Mg}^{2+}$ binding site, a HATPase energizing domain, and a receiver REC domain (Figure 4). Interestingly, StoS is activated by sensing low-oxygen concentrations, and it is involved in stress tolerance and virulence (Ikawa et al., 2014). As shown on Figure 4, the Pseudomonas fluorescens Pf0-1 HyHK, -as well as StoS-, shows domain homology with the BaeS HK, and to a lesser extend to the AtoS HK (Figure 4). In E. coli, the two component system (TCS) AtoSC has been involved in modulating diverse fundamental cellular processes such as short-chain fatty acid catabolism, poly-(R)-3-hydroxybutyrate biosynthesis and chemotaxis (Kyriakidis and Tiligada, 2009). In E. coli, the BaeSR TCS is involved in response to severe envelope stress like spheroplasting (Raffa and Raivio, 2002). Recently, it has been shown that, in Salmonella enterica serovar Typhimurium, BaeSR is required for expression of $\operatorname{sod} A$ and possibly of $\operatorname{sodB}$, encoding two major SODs that are involved in ROS detoxification (Guerrero et al., 2013).

\section{THE CASE OF Pseudomonas aeruginosa}

Dealing with Pseudomonas without mentioning its best known representative species, Pseudomonas aeruginosa, should appear incomplete, but its absence all throughout this review was only motivated by the lack of the tspo analog in the genome of

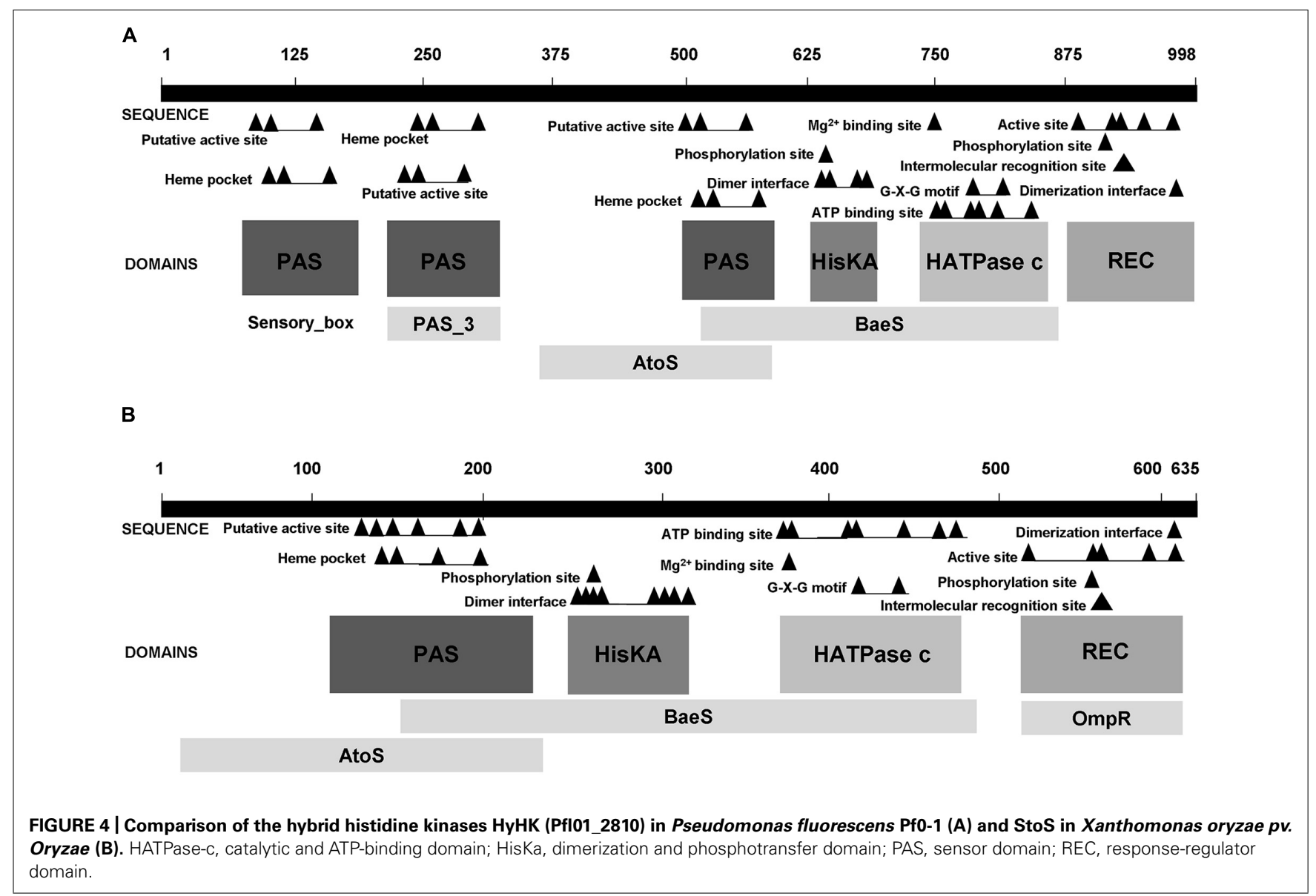


Pseudomonas aeruginosa. Moreover, all attempts to identify even a truncated or partly deleted tspo sequence in Pseudomonas aeruginosa sequenced genomes were failures (Chapalain et al., 2009; Fan et al., 2012). This observation could appear as a simple illustration of the highly variable expression of bacterial TSPO. However, the situation should be more complex. Indeed, it has been shown that benzodiazepines improve the recovery of animals in the Pseudomonas aeruginosa-infected burned mouse model (Dugan et al., 2010), and a detailed analysis of the data indicates that the effect of benzodiazepines on the healing process is not due to direct stimulation of cutaneous cicatrization (Egydio et al., 2012). It is likely that there is no direct effect of benzodiazepines on Pseudomonas aeruginosa but the effects seen is due ot the modulatory effect of benzodiazepines on the immune system (Egydio etal., 2012). This is similar to the case of epinephrine, known since 1930 to have a major impact on bacterial infections but whose direct effect on bacteria was only recognized by the end of the 20th century (Lyte and Ernst, 1992) - well before its bacterial sensor was identified (Clarke et al., 2006; Hughes and Sperandio, 2008). In fact, although Pseudomonas aeruginosa does not express TSPO, its large genome encodes many sensors (receptors) and transporters and different porins, including OprF. In addition, other studies indicated that benzodiazepine analogs can exhibit in vitro direct antibacterial activities on Pseudomonas aeruginosa (Sharma et al., 2013), suggesting that Pseudomonas aeruginosa can sense benzodiazepines. Considering these findings, we cannot exclude the possibility that a sensor protein showing functional homologies with TSPO is expressed in Pseudomonas aeruginosa.

Interestingly, the budding yeast Saccharomyces cerevisiae is known to lack TSPO, which may be due to the loss of almost $90 \%$ of duplicated genes in this organism (Kellis et al., 2004). This characteristic makes Saccharomyces cerevisiae well-suited for heteroexpression studies and an ideal model system for studying the biochemical and pharmacological properties of TSPO (Riond et al., 1991). However, the lack of TSPO in Saccharomyces. cerevisiae also shows that TSPO is not essential for yeast viability and therefore other pathways could perform the functions attributed to the TSPO in other organisms.

\section{CONCLUSION}

TSPO is a protein whose typical five trans-membrane helix structure has been remarkably preserved along the evolutionary process, but whose localization and functions evolved from $\alpha$ - and $\gamma$ proteobacteria to eukaryotes. As a membrane protein, TSPO may be involved in redox and iron homeostasis, and virulence expression as its regulatory networks could be intimately intermingled. As is the case with mitochondria, in Pseudomonas, bacterial TSPO could also take part in signal transduction and in establishing membrane integrity. As a result, TSPO appears to be a vital protein in fluorescent Pseudomonas.

\section{AUTHOR CONTRIBUTIONS}

Charlène Leneveu-Jenvrin, Nathalie Connil, Emeline Bouffartigues, Vassilios Papadopoulos, Marc G. J. Feuilloley, Sylvie Chevalier wrote the manuscript and performed the in silico analysis.

\section{ACKNOWLEDGMENTS}

Charlène Leneveu-Jenvrin is a recipient of a doctoral fellowship from the région Haute-Normandie (GRRHN-SéSa). This study was supported by grants from the Conseil Général de l'Eure, the Grand Evreux Agglomeration, the Région HauteNormandie (GRRHN-Sésa), FEDER funds and a grant from the Canadian Institutes of Health Research. Vassilios Papadopoulos was supported by a Canada Research Chair.

\section{REFERENCES}

Aravind, L., Anand, S., and Iyer, L. M. (2013). Novel autoproteolytic and DNA-damage sensing components in the bacterial SOS response and oxidized methylcytosine-induced eukaryotic DNA demethylation systems. Biol. Dir. 8, 20. doi: $10.1186 / 1745-6150-8-20$

Arvizu-Gomez, J. L., Hernandez-Morales, A., Aguilar, J. R., and Alvarez-Morales, A. (2013). Transcriptional profile of P. syringae pv. phaseolicola NPS3121 at low temperature: physiology of phytopathogenic bacteria. BMC Microbiol. 13:81. doi: 10.1186/1471-2180-13-81

Austin, C. J., Kahlert, J., Kassiou, M., and Rendina, L. M. (2013). The translocator protein (TSPO): a novel target for cancer chemotherapy. Int. J. Biochem. Cell Biol. 45, 1212-1216. doi: 10.1016/j.biocel.2013.03.004

Balsemão-Pires, E., Jaillais, Y., Olson, B. J., Andrade, L. R., Umen, J. G., Chory, J., et al. (2011). The Arabidopsis translocator protein (AtTSPO) is regulated at multiple levels in response to salt stress and perturbations in tetrapyrrole metabolism. BMC Plant Biol. 11:108. doi: 10.1186/1471-2229-11-108

Batarseh, A., and Papadopoulos, V. (2010). Regulation of translocator protein 18 $\mathrm{kDa}$ (TSPO) expression in health and disease states. Mol. Cell. Endocrinol. 327, 1-12. doi: 10.1016/j.mce.2010.06.013

Bauer, C. (2004). Regulation of photosystem synthesis in Rhodobacter capsulatus. Photosynth. Res. 80, 353-360. doi: 10.1023/B:PRES.0000030440.99968.68

Becerra, A., and Lazcano, A. (1998). The role of gene duplication in the evolution of purine nucleotide salvage pathways. Orig. Life Evol. Biosph. 28, 539-553. doi: 10.1023/A:1006500327962

Beinert, H., Holm, R. H., and Munck, E. (1997). Iron-sulfur clusters: nature's modular, multipurpose structures. Science 277, 653-659. doi: 10.1126/science.277.5326.653

Bird, C., Lynch, J., Pirt, F., Reid, W., and Brooks, C. (1971). Steroids and squalene in Methylococcus capsulatus grown on methane. Nature 230, 473-474. doi: 10.1038/230473a0

Bode, H. B., Zeggel, B., Silakowski, B., Wenzel, S. C., Reichenbach, H., and Müller, R. (2003). Steroid biosynthesis in prokaryotes: identification of myxobacterial steroids and cloning of the first bacterial 2,3(S)-oxidosqualene cyclase from the myxobacterium Stigmatella aurantiaca. Mol. Microbiol. 47, 471-481. doi: 10.1046/j.1365-2958.2003.03309.x

Boutigny, S., Saini, A., Baidoo, E. E., Yeung, N., Keasling, J. D., and Butland, G. (2013). Physical and functional interactions of a monothiol glutaredoxin and an iron sulfur cluster carrier protein with the sulfur-donating radical $S$ adenosyl-L-methionine enzyme MiaB. J. Biol. Chem. 288, 14200-14211. doi: 10.1074/jbc.M113.460360

Braestrup, C., and Squires, R. F. (1977). Specific benzodiazepine receptors in rat brain characterized by high-affinity $(3 \mathrm{H})$ diazepam binding. Proc. Natl. Acad. Sci. U.S.A. 74, 3805-3809. doi: 10.1073/pnas.74.9.3805

Cabiscol, E., Tamarit, J., and Ros, J. (2000). Oxidative stress in bacteria and protein damage by reactive oxygen species. Int. Microbiol. 3, 3-8.

Chapalain, A., Chevalier, S., Orange, N., Murillo, L., Papadopoulos, V., and Feuilloley, M. G. (2009). Bacterial ortholog of mammalian translocator protein (TSPO) with virulence regulating activity. PLoS ONE 4:e6096. doi: 10.1371/journal.pone.0006096

Chen, H., and Boutros, P. C. (2011). Venn Diagram: a package for the generation of highly-customizable Venn and Euler diagrams in R. BMC Bioinformatics 12:35. doi: 10.1186/1471-2105-12-35

Choi, J., Ifuku, M., Noda, M., and Guilarte, T. R. (2011). Translocator protein $(18 \mathrm{kDa}) /$ peripheral benzodiazepine receptor specific ligands induce microglia functions consistent with an activated state. Glia 59, 219-230. doi: 10.1002/glia.21091

Chung, J. Y., Chen, H., Midzak, A., Burnett, A. L., Papadopoulos, V., and Zirkin, B. R. (2013). Drug ligand-induced activation of translocator protein (TSPO) stimulates 
steroid production by aged brown Norway rat Leydig cells. Endocrinology 154, 2156-2165. doi: 10.1210/en.2012-2226

Clarke, M. B., Hughes, D. T., Zhu, C., Boedeker, E. C., and Sperandio, V. (2006). The QseC sensor kinase: a bacterial adrenergic receptor. Proc. Natl. Acad. Sci. U.S.A. 103, 10420-10425. doi: 10.1073/pnas.0604343103

Cornelis, P. (2010). Iron uptake and metabolism in pseudomonads. Appl. Microbiol. Biotechnol. 86, 1637-1645. doi: 10.1007/s00253-010-2550-2

Couturier, J., Ströher, E., Albetel, A. N., Roret, T., Muthuramalingam, M., Tarrago, L., et al. (2011). Arabidopsis chloroplastic glutaredoxin C5 as a model to explore molecular determinants for iron-sulfur cluster binding into glutaredoxins. J. Biol. Chem. 286, 27515-27527. doi: 10.1074/jbc.M111.228726

Davey, M. E., and de Bruijn, F. J. (2000). A homologue of the tryptophan-rich sensory protein TspO and FixL regulate a novel nutrient deprivation-induced Sinorhizobium meliloti locus. Appl. Environ. Microbiol. 66, 5353-5359. doi: 10.1128/AEM.66.12.5353-5359.2000

Delavoie, F., Li, H., Hardwick, M., Robert, J. C., Giatzakis, C., Péranzi, G., et al. (2003). In vivo and in vitro peripheral-type benzodiazepine receptor polymerization: functional significance in drug ligand and cholesterol binding. Biochemistry 42, 4506-4519. doi: 10.1021/bi0267487

Desmond, E., and Gribaldo, S. (2009). Phylogenomics of sterol synthesis: insights into the origin, evolution, and diversity of a key eukaryotic feature. Genome Biol. Evol. 1, 364-381. doi: 10.1093/gbe/evp036

Dickens, A. M., Vainio, S., Marjamäki, P., Johansson, J., Lehtiniemi, P., Rokka, J., et al. (2014). Detection of microglial activation in an acute model of neuroinflammation using PET and radiotracers 11C-(R)-PK 11195 and 18F-GE-180. J. Nucl. Med. 55, 466-472. doi: 10.2967/jnumed.113.125625

Dugan, A. L., Gregerson, K. A., Neely, A., Gardner, J., Noel, G. J., Babcock, G. F., et al. (2010). Mice treated with a benzodiazepine had an improved survival rate following Pseudomonas aeruginosa infection. J. Burn Care Res. 31, 1-12. doi: 10.1097/BCR.0b013e3181cb8e82

Egydio, F., Pires, G. N., Tufik, S., and Andersen, M. L. (2012). Wound-healing and benzodiazepines: does sleep play a role in this relationship? Clinics 67, 827-830. doi: 10.6061/clinics/2012(07)20

Fan, J., Lindemann, P., Feuilloley, M. G., and Papadopoulos, V. (2012). Structural and functional evolution of the translocator protein $(18 \mathrm{kDa})$. Curr. Mol. Med. 12, 369-386.

Fantini, J., and Barrantes, F. J. (2013). How cholesterol interacts with membrane proteins: an exploration of cholesterol-binding sites including CRAC, CARC, and tilted domains. Front. Physiol. 4:31. doi: 10.3389/fphys.2013.00031

Finkelstein, R. R., Gampala, S. S., and Rock, C. D. (2002). Abscisic acid signaling in seeds and seedlings. Plant Cell 14(Suppl.), S15-S45. doi: 10.1105/tpc. 010441

Fischer, R., Schmitt, M., Bode, J. G., and Häussinger, D. (2001). Expression of the peripheral-type benzodiazepine receptor and apoptosis induction in hepatic stellate cells. Gastroenterology 120, 1212-1226. doi: 10.1053/gast.2001. 23260

Fito-Boncompte, L., Chapalain, A., Bouffartigues, E., Chaker, H., Lesouhaitier, O., Gicquel, G., et al. (2011). Full virulence of Pseudomonas aeruginosa requires OprF. Infect. Immun. 79, 1176-1186. doi: 10.1128/IAI.00850-10

Frank, W., Baar, K. M., Qudeimat, E., Woriedh, M., Alawady, A., Ratnadewi, D., et al. (2007). A mitochondrial protein homologous to the mammalian peripheral-type benzodiazepine receptor is essential for stress adaptation in plants. Plant J. 51, 1004-1018. doi: 10.1111/j.1365-313X.2007.03198.x

Furre, I. E., Shahzidi, S., Luksiene, Z., Møller, M. T., Borgen, E., Morgan, J., et al. (2005). Targeting PBR by hexaminolevulinate-mediated photodynamic therapy induces apoptosis through translocation of apoptosis-inducing factor in human leukemia cells. Cancer Res. 65, 11051-11060. doi: 10.1158/0008-5472.CAN-050510

Gawas, D., Garcia, R., Huch, V., and Müller, R. (2011). A highly conjugated dihydroxylated C28 steroid from a myxobacterium. J. Nat. Prod. 74, 1281-1283. doi: $10.1021 / \mathrm{np} 100682 \mathrm{c}$

Ginter, C., Kiburu, I., and Boudker, O. (2013). Chemical catalysis by the translocator protein (18 kDa). Biochemistry 52, 3609-3611. doi: 10.1021/bi400364z

Goldman, B. S., Beck, D. L., Monika, E. M., and Kranz, R. G. (1998). Transmembrane heme delivery systems. Proc. Natl. Acad. Sci. U.S.A. 95, 5003-5008. doi: 10.1073/pnas.95.9.5003

González, J. M., Pinhassi, J., Fernández-Gómez, B., Coll-Lladó, M., González-Velázquez, M., Puigbò, P., etal. (2011). Genomics of the proteorhodopsin-containing marine flavobacterium Dokdonia sp. strain MED134. Appl. Environ. Microbiol. 77, 8676-8686. doi: 10.1128/AEM.06152-11

Gray, M. W., Burger, G., and Lang, B. F. (2001). The origin and early evolution of mitochondria. Genome Biol. 2:1018. doi: 10.1186/gb-2001-2-6-reviews 1018

Grossman, M. J., Hinton, S. M., Minak-Bernero, V., Slaughter, C., and Stiefel, E. I. (1992). Unification of the ferritin family of proteins. Proc. Natl. Acad. Sci. U.S.A. 89, 2419-2423. doi: 10.1073/pnas.89.6.2419

Guerrero, P., Collao, B., Álvarez, R., Salinas, H., Morales, E. H., Calderón, I. L., et al. (2013). Salmonella enterica serovar Typhimurium BaeSR two-component system positively regulates sodA in response to ciprofloxacin. Microbiology 159, 2049-2057. doi: 10.1099/mic.0.066787-0

Guillaumot, D., Guillon, S., Deplanque, T., Vanhee, C., Gumy, C., Masquelier, D., et al. (2009a). The Arabidopsis TSPO-related protein is a stress and abscisic acidregulated, endoplasmic reticulum-Golgi-localized membrane protein. Plant J. 60, 242-256. doi: 10.1111/j.1365-313X.2009.03950.x

Guillaumot, D., Guillon, S., Morsomme, P., and Batoko, H. (2009b). ABA, porphyrins and plant TSPO-related protein. Plant Signal. Behav. 4, 1087-1090. doi: $10.4161 /$ psb.4.11.9796

Guillemet, E., Tran, S. L., Cadot, C., Rognan, D., Lereclus, D., and Ramarao, N. (2013). Glucose 6P binds and activates HlyIIR to repress Bacillus cereus haemolysin hlyII gene expression. PLoS ONE 8:e55085. doi: 10.1371/journal.pone.0055085

Harberts, E., Datta, D., Chen, S., Wohler, J. E., Oh, U., and Jacobson, S. (2013). Translocator protein $18 \mathrm{kDa}$ (TSPO) expression in multiple sclerosis patients. J. Neuroimmune Pharmacol. 8, 51-57. doi: 10.1007/s11481-0129397-5

Henderson, B., Fares, M. A., and Lund, P. A. (2013). Chaperonin 60: a paradoxical, evolutionarily conserved protein family with multiple moonlighting functions. Biol. Rev. Camb. Philos. Soc. 88, 955-987. doi: 10.1111/brv.12037

Henry, J. T., and Crosson, S. (2011). Ligand binding PAS domains in a genomic, cellular, and structural context. Annu. Rev. Microbiol. 65, 261-286. doi: 10.1146/annurev-micro-121809-151631

Hirsch, J. D., Beyer, C. F., Malkowitz, L., Loullis, C. C., and Blume, A. J. (1989). Characterization of ligand binding to mitochondrial benzodiazepine receptors. Mol. Pharmacol. 35, 164-172.

Hughes, D. T., and Sperandio, V. (2008). Inter-kingdom signaling: communication between bacteria and their hosts. Nat. Rev. Microbiol. 6, 111-120. doi: 10.1038/nrmicro1836

Ikawa, Y., Furutani, A., Ochiai, H., and Tsuge, S. (2014). StoS, a hybrid histidine kinase sensor of Xanthomonas oryzae pv. oryzae, is activated by sensing low $\mathrm{O} 2$ concentration and is involved in stress tolerance and virulence. Mol. Plant Microbe Interact. 27, 537-545. doi: 10.1094/MPMI-09-13-0263-R

Issop, L., Rone, M. B., and Papadopoulos, V. (2013). Organelle plasticity and interactions in cholesterol transport and steroid biosynthesis. Mol. Cell. Endocrinol. 371, 34-46. doi: 10.1016/j.mce.2012.12.003

Iwema, T., Picciocchi, A., Traore, D. A., Ferrern, J. L., Chauvat, F., and Jacquamet, L. (2009). Structural basis for delivery of the intact [Fe2S2] cluster by monothiol glutaredoxin. Biochemistry 48, 6041-6043. doi: 10.1021/bi900440m

Jamin, N., Neumann, J. M., Ostuni, M. A., Vu, T. K., Yao, Z. X., Murail, S., et al. (2005). Characterization of the cholesterol recognition amino acid consensus sequence of the peripheral-type benzodiazepine receptor. Mol. Endocrinol. 19, 588-594. doi: 10.1210/me.2004-0308

Jaremko, L., Jaremko, M., Giller, K., Becker, S., and Zweckstetter, M. (2014). Structure of the mitochondrial translocator protein in complex with a diagnostic ligand. Science 343, 1363-1366. doi: 10.1126/science.1248725

Kabe, Y., Ohmori, M., Shinouchi, K., Tsuboi, Y., Hirao, S., Azuma, M., et al. (2006). Porphyrin accumulation in mitochondria is mediated by 2-oxoglutarate carrier. J. Biol. Chem. 281, 31729-31735. doi: 10.1074/jbc.M604729200

Kellis, M., Birren, B. W., and Lander, E. S. (2004). Proof and evolutionary analysis of ancient genome duplication in the yeast Saccharomyces cerevisiae. Nature 428, 617-624. doi: 10.1038/nature02424

Kinnally, K. W., Zorov, D. B., Antonenko, Y. N., Snyder, S. H., McEnery, M. W., and Tedeschi, H. (1993). Mitochondrial benzodiazepine receptor linked to inner membrane ion channels by nanomolar actions of ligands. Proc. Natl. Acad. Sci. U.S.A. 90, 1374-1378. doi: 10.1073/pnas.90.4.1374

Krueger, K. E., and Papadopoulos, V. (1990). Peripheral-type benzodiazepine receptors mediate translocation of cholesterol from outer to inner mitochondrial membranes in adrenocortical cells. J. Biol. Chem. 265, 15015-15022. 
Kupper, M., Gupta, S. K., Feldhaar, H., and Gross, R. (2014). Versatile roles of the chaperonin GroEL in microorganism-insect interactions. FEMS Microbiol. Lett. 353, 1-10. doi: 10.1111/1574-6968.12390

Kyriakidis, D. A., and Tiligada, E. (2009). Signal transduction and adaptive regulation through bacterial two-component systems: the Escherichia coli AtoSC paradigm. Amino Acids 37, 443-458. doi: 10.1007/s00726-009-0241-z

Lacapère, J. J., Delavoie, F., Li, H., Péranzi, G., Maccario, J., Papadopoulos, V., et al. (2001). Structural and functional study of reconstituted peripheral benzodiazepine receptor. Biochem. Biophys. Res. Commun. 284, 536-541. doi: 10.1006/bbrc.2001.4975

Lacapère, J. J., and Papadopoulos, V. (2003). Peripheral-type benzodiazepine receptor: structure and function of a cholesterol-binding protein in steroid and bile acid biosynthesis. Steroids 68, 569-585. doi: 10.1016/S0039-128X(03) 00101-6

Le Fur, G., Guilloux, F., Rufat, P., Benavides, J., Uzan, A., Renault, C., et al. (1983). Peripheral benzodiazepine binding sites: effect of PK 11195, 1-(2-chlorophenyl)$N$-methyl-(1-methylpropyl)-3 isoquinolinecarboxamide. Life Sci. 32, 1849-1856. doi: 10.1016/0024-3205(83)90063-2

Lenaz, G. (1998). Role of mitochondria in oxidative stress and ageing. Biochim. Biophys. Acta 1366, 53-67. doi: 10.1016/S0005-2728(98)00120-0

Lehtonen, M. T., Akita, M., Frank, W., Reski, R., and Valkonen, J. P. (2012). Involvement of a class III peroxidase and the mitochondrial protein TSPO in oxidative burst upon treatment of moss plants with a fungal elicitor. Mol. Plant Microbe Interact. 25, 363-371. doi: 10.1094/MPMI-10-11-0265

Leung, W. Y., Hamazaki, T., Ostrov, D. A., and Terada, N. (2013). Identification of adenine nucleotide translocase 4 inhibitors by molecular docking. J. Mol. Graph Model. 45, 173-179. doi: 10.1016/j.jmgm.2013.08.016

Levine, S. L., Han, Z., Liu, J., Farmer, D. R., and Papadopoulos, V. (2007). Disrupting mitochondrial function with surfactants inhibits MA-10 Leydig cell steroidogenesis. Cell Biol. Toxicol. 23, 385-400. doi: 10.1007/s10565-007-9001-6

Li, H., and Papadopoulos, V. (1998). Peripheral-type benzodiazepine receptor function in cholesterol transport: identification of a putative cholesterol recognition/interaction amino acid sequence and consensus pattern. Endocrinology 139, 4991-4997.

Lillig, C. H., Berndt, C., and Holmgren, A. (2008). Glutaredoxin systems. Biochim. Biophys. Acta 1780, 1304-1317. doi: 10.1016/j.bbagen.2008.06.003

Lindemann, P., Koch, A., Degenhardt, B., Hause, G., Grimm, B., and Papadopoulos, V. (2004). A novel Arabidopsis thaliana protein is a functional peripheral-type benzodiazepine receptor. Plant Cell Physiol. 45, 723-733. doi: 10.1093/pcp/pch088

López-Garćia, P., and Moreira, D. (1999). Metabolic symbiosis at the origin of eukaryotes. Trends Biochem. Sci. 24, 88-93. doi: 10.1016/S0968-0004(98)01342-5

Lyte, M., and Ernst, S. (1992). Catecholamine induced growth of gram negative bacteria. Life Sci. 50, 203-212. doi: 10.1016/0024-3205(92)90273-R

Mapolelo, D. T., Zhang, B., Randeniya, S., Albetel, A. N., Li, H., Couturier, J., et al. (2013). Monothiol glutaredoxins and A-type proteins: partners in Fe-S cluster trafficking. Dalton Trans. 42, 3107-3115. doi: 10.1039/c2dt32263c

McEnery, M. W. (1992). The mitochondrial benzodiazepine receptor: evidence for association with the voltage-dependent anion channel (VDAC). J. Bioenerg. Biomembr. 24, 63-69. doi: 10.1007/BF00769532

Mesenholler, M., and Matthews, E. K. (2000). A key role for the mitochondrial benzodiazepine receptor in cellular photosensitisation with delta-aminolaevulinic acid. Eur. J. Pharmacol. 406, 171-180. doi: 10.1016/S0014-2999(00)00646-4

Miller, W. L., and Bose, H. S. (2011). Early steps in steroidogenesis: intracellular cholesterol trafficking. Lipid Res. 52, 2111-2135. doi: 10.1194/jlr.R016675

Mishra, S., and Imlay, J. (2012). Why do bacteria use so many enzymes to scavenge hydrogen peroxide? Arch. Biochem. Biophys. 525, 145-160. doi: 10.1016/j.abb.2012.04.014

Mochizuki, N., Tanaka, R., Grimm, B., Masuda, T., Moulin, M., Smith, A. G., et al. (2010). The cell biology of tetrapyrroles: a life and death struggle. Trends Plant Sci. 15, 488-498. doi: 10.1016/j.tplants.2010.05.012

Morohaku, K., Pelton, S. H., Daugherty, D. J., Butler, W. R., Deng, W., and Selvaraj, V. (2014). Translocator protein/peripheral benzodiazepine receptor is not required for steroid hormone biosynthesis. Endocrinology 155, 89-97. doi: 10.1210/en.2013-1556

Mühlenhoff, U., Molik, S., Godoy, J. R., Uzarska, M. A., Richter, N., Seubert, A., et al. (2010). Cytosolic monothiol glutaredoxins function in intracellular iron sensing and trafficking via their bound iron-sulfur cluster. Cell Metab. 12, 373-385. doi: 10.1016/j.cmet.2010.08.001
Nambara, E., and Marion-Poll, A. (2005). Abscisic acid biosynthesis and catabolism. Annu. Rev. Plant Biol. 56, 165-185. doi: 10.1146/annurev.arplant. 56.032604 .144046

Oh, J. I., and Kaplan, S. (2001). Generalized approach to the regulation and integration of gene expression. Mol. Microbiol. 39, 1116-1123. doi: 10.1111/j.1365-2958.2001.02299.x

Oke, B. O., Suarez-Quia, C. A., Riond, J., Ferrara, P., and Papadopoulos, V. (1992) Cell surface localization of the peripheral-type benzodiazepine receptor (PBR) in adrenal cortex. Mol. Cell. Endocrinol. 87, 1-6. doi: 10.1016/0303-7207(92) 90248-5

Otera, H., Taira, Y., Horie, C., Suzuki, Y., Suzuki, H., Setoguchi, K., et al. (2007). A novel insertion pathway of mitochondrial outer membrane proteins with multiple transmembrane segments. J. Cell Biol. 179, 1355-1363. doi: $10.1083 /$ jcb. 200702143

Ourisson, G., and Nakatani, Y. (1994). The terpenoid theory of the origin of cellular life: the evolution of terpenoids to cholesterol. Chem. Biol. 1, 11-23. doi: 10.1016/1074-5521(94)90036-1

Papadopoulos, V. (2014). On the role of the translocator protein (18-kDa) TSPO in steroid hormone biosynthesis. Endocrinology 155, 15-20. doi: 10.1210/en. 2013-2033

Papadopoulos, V., Amri, H., Boujrad, N., Papadopoulos, V., Amri, H., Boujrad, N., et al. (1997a). Peripheral benzodiazepine receptor in cholesterol transport and steroidogenesis. Steroids 62, 21-28. doi: 10.1016/S0039-128X(96)00154-7

Papadopoulos, V., Amri, H., Li, H., Boujrad, N., Vidic, B., and Garnier, M. (1997b). Targeted disruption of the peripheral-type benzodiazepine receptor gene inhibits steroidogenesis in the R2C Leydig tumor cell line. J. Biol. Chem. 272, 3212932135. doi: 10.1074/jbc.272.51.32129

Papadopoulos, V., Baraldi, M., Guilarte, T. R., Papadopoulos, V., Baraldi, M., Guilarte, T. R., et al. (2006). Translocator protein (18 kDa): new nomenclature for the peripheral-type benzodiazepine receptor based on its structure and molecular function. Trends Pharmacol. Sci. 27, 402-409. doi: 10.1016/j.tips.2006.06.005

Papadopoulos, V., Mukhin, A. G., Costa, E., and Krueger, K. E. (1990). The peripheral-type benzodiazepine receptor is functionally linked to Leydig cell steroidogenesis. J. Biol. Chem. 265, 3772-3779.

Papadopoulos, V., Liu, J., and Culty, M. (2007). Is there a mitochondrial signaling complex facilitating cholesterol import? Mol. Cell. Endocrinol. 265-266, 59-64. doi: 10.1016/j.mce.2006.12.004

Picot, L., Mezghani-Abdelmoula, S., Chevalier, S., Merieau, A., Lesouhaitier, O., Guerillon, J., et al. (2004). Regulation of the cytotoxic effects of Pseudomonas fluorescens by growth temperature. Res. Microbiol. 155, 39-46. doi: 10.1016/j.resmic.2003.09.014

Poderoso, C., Duarte, A., Cooke, M., Orlando, U., Gottifredi, V., Solano, A. R., et al. (2013). The spatial and temporal regulation of the hormonal signal. Role of mitochondria in the formation of a protein complex required for the activation of cholesterol transport and steroids synthesis. Mol. Cell. Endocrinol. 371, 26-33. doi: 10.1016/j.mce.2012.12.024

Porter, J. A., Young, K. E., and Beachy, P. A. (1996). Cholesterol modification of hedgehog signaling proteins in animal development. Science 274, 255-259. doi: 10.1126/science.274.5285.255

Raffa, R. G., and Raivio, T. L. (2002). A third envelope stress signal transduction pathway in Escherichia coli. Mol. Microbiol. 45, 1599-1611. doi: 10.1046/j.13652958.2002.03112.x

Riond, J., Leplatois, P., Laurent, P., Le Fur, G., Caput, D., Loison, G., et al. (1991). Expression and pharmacological characterization of the human peripheraltype benzodiazepine receptor in yeast. Eur. J. Pharmacol. 208, 307-312. doi: 10.1016/0922-4106(91)90076-T

Rone, M. B., Liu, J., Blonder, J., Ye, X., Veenstra, T. D., Young, J. C., et al. (2009). Targeting and insertion of the cholesterol-binding translocator protein into the outer mitochondrial membrane. Biochemistry 48, 6909-6920. doi: 10.1021/bi900854z

Rone, M. B., Midzak, A. S., Issop, L., Rammouz, G., Jagannathan, S., Fan, J., et al. (2012). Identification of a dynamic mitochondrial protein complex driving cholesterol import, trafficking, and metabolism to steroid hormones. Mol. Endocrinol. 26, 1868-1882. doi: 10.1210/me.2012-1159

Ruff, M. R., Pert, C. B., Weber, R. J., Wahl, L. M., Wahl, S. M., and Paul, S. M. (1985). Benzodiazepine receptor-mediated chemotaxis of human monocytes. Science 229, 1281-1283. doi: 10.1126/science.2994216

Rupprecht, R., Papadopoulos, V., Rammes, G., Bagha, T. C., Fan, J., Akula, N., et al. (2010). Translocator protein $(18 \mathrm{kDa})$ (TSPO) as a therapeutic target for 
neurological and psychiatric disorders. Nat. Rev. Drug Discov. 9, 971-988. doi: $10.1038 / \mathrm{nrd} 3295$

Rupprecht, R., Rammes, G., Eser, D., Baghai, T. C., Schüle, C., Nothdurfter, C., et al. (2009). Translocator protein $(18 \mathrm{kD})$ as target for anxiolytics without benzodiazepine-like side effects. Science 325, 490-493. doi: 10.1126/science. 1175055

Sharma, P. C., Kumar, R., Chaudhary, M., Sharma, A., and Rajak, H. (2013). Synthesis and biological evaluation of novel benzothiazole clubbed fluoroquinolone derivatives. J. Enzyme Inhib. Med. Chem. 28, 1-10. doi: 10.3109/ 14756366.2011.611943

Staudinger, B. J., Muller, J. F., Halldorsson, S., Boles, B., Angermeyer, A., Nguyen, D., et al. (2014). Conditions associated with the cystic fibrosis defect promote chronic Pseudomonas aeruginosa infection. Am. J. Respir. Crit. Care Med. 189, 812-824. doi: 10.1164/rccm.201312-2142OC

Stehling, O., Wilbrecht, C., and Lill, R. (2014). Mitochondrial iron-sulfur protein biogenesis and human disease. Biochimie 100, 61-77. doi: 10.1016/j.biochi. 2014.01.010

Stock, A. M., Robinson, V. L., and Goudreau, P. N. (2000). Two-component signal transduction. Annu. Rev. Biochem. 69, 183-215. doi: 10.1146/annurev.biochem. 69.1.183

Taketani, S., Kohno, H., Furukawa, T., and Tokunaga, R. (1995). Involvement of peripheral-type benzodiazepine receptors in the intracellular transport of heme and porphyrins. J. Biochem. 117, 875-880.

Tippelt, A., Jahnke, L., and Poralla, K. (1998). Squalene-hopene cyclase from Methylococcus capsulatus (Bath): a bacterium producing hopanoids and steroids. Biochim. Biophys. Acta. 1391, 223-232. doi: 10.1016/S0005-2760(97) 00212-9

Tomasch, J., Gohl, R., Bunk, B., Diez, M. S., and Wagner-Dobler, I. (2011). Transcriptional response of the photoheterotrophic marine bacterium Dinoroseobacter shibae to changing light regimes. ISME J. 5, 1957-1968. doi: 10.1038/ismej.2011.68

Tu, L. N., Morohaku, K., Manna, P. R., Pelton, S. H., Butler, W. R., Stocco, D. M., et al. (2014). Peripheral benzodiazepine receptor/translocator protein global knock-out mice are viable with no effects on steroid hormone biosynthesis. J. Biol. Chem. 289, 27444-27454. doi: 10.1074/jbc.M114.578286

Vanhee, C., Zapotoczny, G., Masquelier, D., Ghislain, M., and Batoko, H. (2011) The Arabidopsis multistress regulator TSPO is a heme binding membrane protein and a potential scavenger of porphyrins via an autophagy-dependent degradation mechanism. Plant Cell 23, 785-805. doi: 10.1105/tpc.110.081570

Veenman, L., Papadopoulos, V., and Gavish, M. (2007). Channel-like functions of the $18-\mathrm{kDa}$ translocator protein (TSPO): regulation of apoptosis and steroidogenesis as part of the host-defense response. Curr. Pharm. Des. 13, 2385-2405. doi: $10.2174 / 138161207781368710$

Veljanovski, V., and Batoko, H. (2014). Selective autophagy of non-ubiquitylated targets in plants: looking for cognate receptor/adaptor proteins. Front. Plant Sci. 5:308. doi: 10.3389/fpls.2014.00308

von Mering, C., Jensen, L. J., Kuhn, M., Chaffron, S., Doerks, T., Kruger, B., et al. (2007). STRING 7: recent developments in the integration and prediction of protein interactions. Nucleic Acids Res. 35, D358-D362. doi: 10.1093/nar/ gkl825

Wagner, V. E., Frelinger, J. G., Barth, R. K., and Iglewski, B. H. (2006). Quorum sensing: dynamic response of Pseudomonas aeruginosa to external signals. Trends Microbiol. 14, 55-58. doi: 10.1016/j.tim.2005.12.002

Wang, J. K., Morgan, J. I., and Spector, S. (1984). Benzodiazepines that bind at peripheral sites inhibit cell proliferation. Proc. Natl. Acad. Sci. U.S.A. 81, 753-756. doi: 10.1073/pnas.81.3.753

Wendler, G., Lindemann, P., Lacapère, J. J., and Papadopoulos, V. (2003). Protoporphyrin IX binding and transport by recombinant mouse PBR. Biochem. Biophys. Res. Commun. 311, 847-852. doi: 10.1016/j.bbrc.2003.10.070

Winsor, G. L., Lam, D. K., Fleming, L., Lo, R., Whiteside, M. D., Yu, N. Y., et al. (2011). Pseudomonas genome database: improved comparative analysis and population genomics capability for Pseudomonas genomes. Nucleic Acids Res. 39, 596-600 doi: 10.1093/nar/gkq869

Woods, M. J., and Williams, D. C. (1996). Multiple forms and locations for the peripheral-type benzodiazepine receptor. Biochem. Pharmacol. 52, 1805-1814. doi: 10.1016/S0006-2952(96)00558-8

Woods, M. J., Zisterer, D. M., and Williams, D. C. (1996). Two cellular and subcellular locations for the peripheral-type benzodiazepine receptor in rat liver. Biochem. Pharmacol. 51, 1283-1292. doi: 10.1016/0006-2952(96)00034-2

Wu, L., Estrada, O., Zaborina, O., Bains, M., Shen, L., Kohler, J. E., et al. (2005). Recognition of host immune activation by Pseudomonas aeruginosa. Science 309, 774-777. doi: 10.1126/science.1112422

Yao, H., Jepkorir, G., Lovell, S., Nama, P. V., Weeratunga, S., Battaile, K. P., et al. (2011). Two distinct ferritin-like molecules in Pseudomonas aeruginosa: the product of the bfrA gene is a bacterial ferritin (FtnA) and not a bacterioferritin (Bfr). Biochemistry 50, 5236-5248. doi: 10.1021/bi2004119

Yeliseev, A. A., and Kaplan, S. (1995). A sensory transducer homologous to the mammalian peripheral-type benzodiazepine receptor regulates photosynthetic membrane complex formation in Rhodobacter sphaeroides 2.4.1. J. Biol. Chem. 270, 21167-21175. doi: 10.1074/jbc.270.36.21167

Yeliseev, A. A., and Kaplan, S. (1999). A novel mechanism for the regulation of photosynthesis gene expression by the TspO outer membrane protein of Rhodobacter sphaeroides 2.4.1. J. Biol. Chem. 274, 21234-21243. doi: 10.1074/jbc.274.30.21234

Yeliseev, A. A., and Kaplan, S. (2000). TspO of Rhodobacter sphaeroides. A structural and functional model for the mammalian peripheral benzodiazepine receptor. J. Biol. Chem. 275, 5657-5667. doi: 10.1074/jbc.275.8.5657

Yeliseev, A. A., Krueger, K. E., and Kaplan, S. (1997). A mammalian mitochondrial drug receptor functions as a bacterial "oxygen" sensor. Proc. Natl. Acad. Sci. U.S.A. 94, 5101-5106. doi: 10.1073/pnas.94.10.5101

Zeng, X., and Kaplan, S. (2001). TspO as a modulator of the repressor/antirepressor (PpsR/AppA) regulatory system in Rhodobacter sphaeroides 2.4.1. J. Bacteriol. 183, 6355-6364. doi: 10.1128/JB.183.21.6355-6364.2001

Zeno, S., Zaaroor, M., Leschiner, S., Veenman, L., and Gavish, M. (2009). CoCl2 induces apoptosis via the $18 \mathrm{kDa}$ translocator protein in U118MG human glioblastoma cells. Biochemistry 48, 4652-4661. doi: 10.1021/bi900064t

Zhang, F., Scheerer, P., Oberpichler, I., Lamparter, T., and Krauss, N. (2013). Crystal structure of a prokaryotic (6-4) photolyase with an Fe-S cluster and a 6,7dimethyl-8-ribityllumazine antenna chromophore. Proc. Natl. Acad. Sci. U.S.A. 110, 7217-7222. doi: 10.1073/pnas.1302377110

Zheng, M., Wang, X., Doan, B., Lewis, K. A., Schneider, T. D., and Storz, G. (2001). Computation-directed identification of OxyR DNA binding sites in Escherichia coli. J. Bacteriol. 183, 4571-4579. doi: 10.1128/JB.183.15.4571-4579.2001

Conflict of Interest Statement: The authors declare that the research was conducted in the absence of any commercial or financial relationships that could be construed as a potential conflict of interest.

Received: 03 August 2014; accepted: 04 November 2014; published online: 19 November 2014.

Citation: Leneveu-Jenvrin C, Connil N, Bouffartigues E, Papadopoulos V, Feuilloley MGJ and Chevalier S (2014) Structure-to-function relationships of bacterial translocator protein (TSPO): a focus on Pseudomonas. Front. Microbiol. 5:631. doi: 10.3389/fmicb.2014.00631

This article was submitted to Evolutionary and Genomic Microbiology, a section of the journal Frontiers in Microbiology.

Copyright (C) 2014 Leneveu-Jenvrin, Connil, Bouffartigues, Papadopoulos, Feuilloley and Chevalier. This is an open-access article distributed under the terms of the Creative Commons Attribution License (CC BY). The use, distribution or reproduction in other forums is permitted, provided the original author(s) or licensor are credited and that the original publication in this journal is cited, in accordance with accepted academic practice. No use, distribution or reproduction is permitted which does not comply with these terms. 